FACULDADE DE CIÊNCIAS ECONÔMICAS DA UFRGS
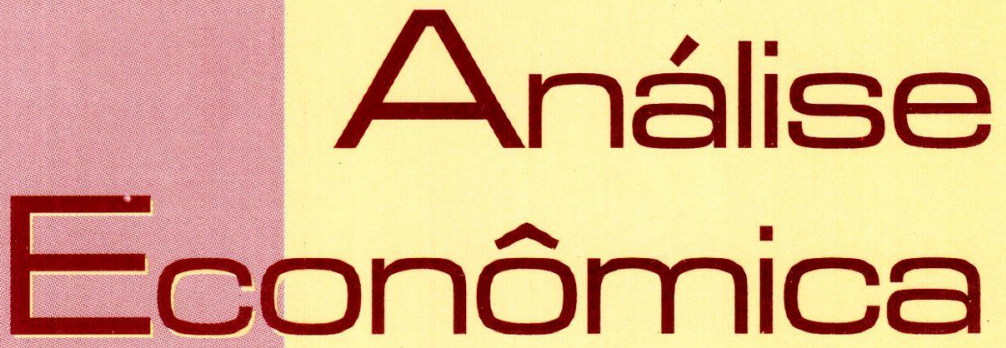

AS LOCOMOTIVAS ENFERRUIADAS

DO CAPITALISMO

Reinaldo Gonçalves

EFICIENNCIA, DESRECULAMENTACC̃O

FINANCEIRA E CRESCIMENTO

ECONOMICO: UMA ABORDAGEM

PÓS-KEYNESIANA

ROGÉRIO SOBREIRA

MERCADOS CONTESTÁVEIS E

COMPEIIÇÃO NO NOVO MODELO

DO SETOR ELÉtRICO BRASILEIRO

ELBIA VINHAES

EDVALDO SANTANa

MICROCRÉDITO: ASPECTOS TEÓRICOS

E EXPERIÊNCIAS

Márcio BobiK Braga

RUDINEI TONETO JR.

A RelaÇão Entre a Política e A ECONOMIA: SUAS IMPLICAÇÓES NO SISTEMA FINANCEIRO

JORGe PESSOA De MENDONĢA

AS RAiZzes CONCEITUAIS DO

INERCIALISMO

VAIDIR RAMAIHO

AUGE E INICIO DO DECLINIIO DA ECONOMIA ARGENTINA

maria Heló́sa lenz

$$
\text { ANO } \begin{array}{r}
18 \\
\text { No } 33
\end{array}
$$

MARÇO, 2000 
Universidade Federal do Rro Grande do Sui

Reitora: Prof ${ }^{a}$. Wrana Maria Panizzi

Faculdade de Ciências Econômicas

Diretora: Prof ${ }^{a}$ Otilia Beatriz Kroeff Carrion

Centro de Estudos e Pesquisas Econômicas

Diretor: Prof. Fernando Ferrari Filho

Departamento de Ciênctás Econòmicas

Chefe: Prof Luiz Alberto Oliveira Ribeiro de Miranda

Curso de Pós-Graduação em Economia

Coordenador: Prof. Marcelo Savino Portugal

Curso de Pós-Graduação em Economia Rural

Coordenador: Prof. Carlos Guilherme A. Mielitz Netto

Consel.ho Editorial:

Achyles B. Costa, Aray M. Feldens, Carlos A. Crusius, Carlos G. A. Mielitz Netto, Eduardo A. Maldonado Filho, Eduardo P. Ribeiro, Eugênio Lagemann, Fernando Ferrari Filho, Gentil Corazza, Marcelo S. Portugal, Nali I. Souza, Otnia B. K Carrion, Paulo A. Spohr, Paulo D. Waquil, Pedro C. D. Fonseca, Roberto C Moraes, Ronald Otto Hillbrecht, Stefano

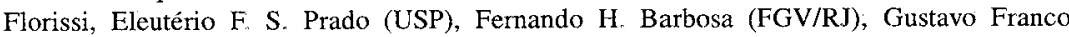
(PUC/RJ), João R. Sanson (UFSC), Joaquim P. Andrade (UnB), Juan H. Moldau (USP), Paul Davidson (Univ. of Tennessee), Werner Baer (Univ. of Illinois).

\section{Comissāo Entrorial:}

Eduardo Augusto Maldonado Filho, Fernando Ferrari Filho, Gentil Corazza, Marcelo Savino Portugal, Paulo Dabdab Waquil; Roberto Camps Moraes.

EorTor: Gentil Corazza

Edrror Adjunto: Pedro Silveira Bandeira

Secretário: Márcio Souza de Vargas

Revisão de Textos: Vanete Ricacheski

Fundador: Prof Antônio Carlos Santos Rosa

Os materiais publicados na revista Análise Econômica são da exclusiva responsabilidade dos autores. É permitida a reprodução total ou parcial dos trabalhos, desde que seja citada a fonte Aceita-se permuta com revistas congêneres. Aceitam-se, também, livros para divulgação, elaboração de resenhas e recensões. Toda correspondência, material para publicação (vide normas na terceira capa), assinaturas e permutas devem ser dirigidos ao seguinte destinatário:

PROF GENTIL CORAZZA

Revista Análise Econômica - Av. João Pessoa, 52

CEP 90040-000 PORTO ALEGRE - RS, BRASIL.

Telefones: (051) 316-3348 e 316-3440 - Fax: (051) 316-3990

E-mail: rae@vortex.ufrgs.br

Análise Econômica

Ano 18, $\mathrm{n}^{\circ} 33$, março, 2000 - Porto Alegre

Faculdade de Ciências Econômicas, UFRGS, 2000

Periodicidade semestral, março e setembro

1. Teoria Econômica - Desenvolvimento Regional -

Economia Agrícola - Pesquisa Teórica e Aplicada -

Periódicos. I. Brasil.

Faculdade de Ciências Econômicas,

Universidade Federal do Rio Grande do Sul. 


\title{
Microcrédito: aspectos teóricos e experiências
}

\author{
Márcio Bobik Braga \\ Rudinei Toneto Jr.
}

\begin{abstract}
Resumo: $O$ trabalho procura discutir as dificuldades de financiamento das microempresas dentro da lógica do sistema financeiro tradicional e como o microcrédito pode resolver este problema. O primeiro ponto do trabalho é mostrar por que as microempresas são excluídas dos financiamentos tradicionais na presença de informações assimétricas. Em seguida, apresenta-se a experiência do Grameen Bank para mostrar como arranjos contratuais específicos podem viabilizar o financiamento de pequenos empreendimentos. $\mathrm{E}$, ao final, apresenta-se a experiência brasileira com microcrédito, destacandose o PROGER (Programa de Geração de Ėmprego e Renda) e as primeiras instituições de microcrédito.
\end{abstract}

Palavras-chave: Microcrédito, sistema financeiro, informação assimétrica.

\begin{abstract}
The main objective of this article is to discuss the financing problems of small business in the traditional financial system and also how the microcredit may solve this problem. The first part shows why this kind of business are excluded from the traditional finance in the presence of assimetric information. Secondly, the experience of Grameen Bank is presented to show how specific contract arrangements can make possible small business finance. Last, the brazilian experience with the microcredit is discussed, making salient the PROGER and the firs institutions to operate with microcredit.
\end{abstract}

Key-words: Microcredit, financial system, assimetric information.

\section{Introdução}

Apesar do crescimento da literatura sobre a influência do sistema financeiro no desenvolvimento econômico, os resultados e as análises ainda são bastante controversos ${ }^{1}$. Vários autores, trabalhando com a hipótese de mercados financeiros perfeitos, concorrência e informações completas e simétricas, procuraram demonstrar a irrelevância da estrutura financeira nas decisões dos agentes, isto é, o sistema financeiro não teria qualquer influên-

\footnotetext{
* Professores do Departamento de Economia da FEA/USP, campus de Ribeirão Preto.

1 A respeito da literatura ver Gertler (1988) e Levine (1997).
} 
cia sobre os" "resultados econômicos": as decisões de poupança e investimento e a melhor alocação da popupança não seria influenciada pela estrutura financeira em mercados livres (Teorema Modigliani-Miller - 1958). Para esta corrente, o sistema financeiro só afetaria o desenvolvimento econômico de forma negativa, em decorrência da intervenção do governo através de excesso de regulamentações, controle e direcionamento de crédito etc. ${ }^{2}$ Com isso, seriam necessárias reformas financeiras pró-mercado (liberalizantes) nos países pouco desenvolvidos, como forma de estimular o desenvolvimento.

Existe, por outro lado, uma ampla literatura que considera a existência de informações assimétricas e custos de transação nos mercados financeiros, decorrentes das especificidades das transações financeiras. Para esta literatura, o mercado de crédito seria caracterizado pela existência de problemas de seleção adversa e risco-moral. Nesse contexto, a solução de mercado livre não necessariamente resulta na alocação ótima dos recursos, podendo haver arranjos contratuais e intervenções que aumentem a eficiência na alocação de recursos. ${ }^{3}$

O fato é que as restrições de liquidez que emergem das características do mercado financeiro afetam as decisões de consumo e as possibilidades de investimento, influindo no desempenho econômico. Se tais restrições existem e decorrem da existência de problemas de informação, a estrutura financeira afeta o crescimento econômico, como enfatizado por vários trabalhos empíricos.

Os problemas decorrentes da informação assimétrica e dos custos de transação, conforme demonstram inúmeros autores, fazem com que o sistema financeiro tenda a assumir um caráter conservador, excluindo determinados segmentos do acesso ao crédito como, por exemplo, população de baixa renda, setor informal, micro e pequena empresas, empresas nascentes, etc., além de privilegiar os financiamentos de curto prazo. ${ }^{4} \mathrm{O}$ problema da exclusão é particularmente grave nos países em desenvolvimento, que caracterizam-se por uma grande participação do setor informal, das micro e pequena empresas e das populações de baixa renda. Assim, se o sistema financeiro não alcança estes segmentos, limita-se a alocação eficiente dos recursos, o investimento e a geração de emprego e renda. O mercado de crédito infor-

${ }^{2}$ Esta influência negativa do sistema financeiro em decorrência de intervenções do governo é conhecida na literatura como teoria da repressão financeira Sobre esta teoria, ver Mackinnon (1973), Shaw (1971) e Fry (1997).

${ }^{3}$ A este repeito ver Stiglitz e Weiss (1981) e Stiglitz (1992).

${ }^{4}$ Sobre os problemas alocativos decorrentes da existência de assimetria de informação, ver Stiglitz (1992) e Mankiw (1986). 
mal, com seus elevados custos, tende a assumir uma importância crucial para esses segmentos, penalizando-os em relação às empresas maiores e à população de alta renda, estimulando ainda mais a concentração de renda.

Para lidar com esse problema, tem surgido em uma série de países do Terceiro Mundo instituições de microcrédito que buscam, por meio de instrumentos alternativos, atender às necessidades de crédito dos segmentos excluídos do sistema financeiro tradicional. Esta preocupação tem sido crescente, principalmente no caso das micro e pequena empresas, tendo em vista o agravamento dos problemas de desemprego mundial e a importância deste segmento na geração de emprego.

O microcrédito tem sido o principal instrumento das chamadas políticas de geração de emprego e renda que surgiram mundo afora, como resposta à crise do emprego. Note-se, porém, que este mecanismo possui uma lógica distinta das políticas assistencialistas tradicionais, visando criar oportunidades de inserção dos beneficiários no processo produtivo. Não constitui-se, portanto, políticas de doações ou subsídios, mas de viabilização de alternativas concretas de geração de emprego e renda pelos beneficiários.

$O$ objetivo do artigo é discutir a questão do financiamento dos micro e pequenos empreendimentos com base na literatura que privilegia os problemas de informação dos mercados de crédito, e discutir o instrumento do microcrédito como uma forma alternativa para o financiamento desses segmentos. $\mathrm{O}$ artigo divide-se em três partes, além desta introdução e da conclusão. Na primeira, pretende-se mostrar como, em um contexto de informação assimétrica, o sistema financeiro pode excluir determinados tipos de empreendimentos, incluindo nesta exclusão as micro e pequenas empresas. Na segunda, é apresentado o caso do Grameen Bank, de Bangladesh, considerada a instituição de microcrédito mais antiga e bem-sucedida do mundo. Conforme veremos, tal instituição vem viabilizando seus empréstimos a partir de um esquema conhecido como de "fiança solidária", que substitui as garantias reais. Na última parte, analisa-se a experiência brasileira com microcrédito.

\section{0 problema do financiamento das empresas de pequeno porte}

Como destacado por uma série de autores, ${ }^{5}$ o mercado de crédito está longe de ser caracterizado, por exemplo, como um mercado de batatas; e o preço acaba não funcionando como market-clearing. Explicando melhor, a

\footnotetext{
${ }^{5}$ Sobre alguns desses autores, ver Braga (1998).
} 
especialidade básica do mercado financeiro é que não se aliena a mercadoria transacionada, o dinheiro, mas apenas a empresta. Ou seja, negocia-se o uso do dinheiro durante um determinado período de tempo. Assim, para o vendedor, ou emprestador, seu lucro depende não apenas do preço cobrado (taxa de juros), mas também da devolução da soma inicialmente emprestada. Do lado do tomador, sua capacidade de pagar o empréstimo depende do projeto financiado com o empréstimo e de sua disposição a pagar. O grande problema nesta transação refere-se à existência de informações assimétricas, em que o tomador de recursos possui melhores condições de avaliar o risco envolvido no projeto financiado e sua disposição a pagar do que o emprestador.

Os custos de informação estão ligados à elaboração de contratos e ao processo de seleção e monitoramento nas operações de empréstimos que visam minimizar os problemas de informação e tendem a levar o sistema financeiro a apresentar um caráter conservador, excluindo segmentos em que tais custos são elevados. Este pode ser o caso de determinadas atividades dentro do setor agrícola, do setor informal e financiamentos destinados a micro e pequenas empresas.

As implicações alocativas decorrentes da existência de assimetria de informação podem ser melhor entendidas a partir da relação entre credor e devedor, que é estabelecida através de contratos de dívida. Além de prever o montante de empréstimos, o período e a taxa de juros, esses contratos procuram estabelecer cláusulas que, além de selecionar os devedores, induza-os a tomar as ações necessárias ao bom andamento do empreendimento financiado, possibilitando o pagamento do empréstimo mais os juros pactuados no prazo previsto.

Muitos autores procuraram estudar algum tipo de "relação contratual ótima" numa operação de empréstimo em situações nas quais existe assimetria de informação entre as partes envolvidas. O trabalho de Townsend (1979) pode ser considerado como uma importante referência para esses estudos. Townsend desenvolve um modelo de trocas (denominado na literatura como The costly state verification model ou simplesmente CSV model), em que os indivíduos são informados assimetricamente e ex-post acerca do estado da natureza, sendo que tal informação só pode ser transmitida entre eles mediante algum custo. ${ }^{6} \mathrm{O}$ modelo considera um acordo bilateral entre o credor $\mathrm{e}$ devedor. O primeiro incorre num custo fixo de observar os retornos do projeto a ser financiado. Por outro lado, o tomador não possui colateral suficiente para oferecer ao banco. $\mathrm{O}$ grande problema que o credor enfrenta refere-se ao

\footnotetext{
${ }^{6} \mathrm{O}$ estado da natureza representa eventos aleatórios que influem no resultado do empreendimento como, por exemplo, o comportamento climático no caso da agricultura ou a demanda futura por um determinado bem.
} 
fato do tomador não ter incentivos em informar adequadamente sobre $o$ andamento do projeto. Para o autor, o contrato ótimo seria aquele que prevê que o tomador deve se submeter, sob determinadas circunstâncias, à verificação e exigência no cumprimento dos termos do contrato. Tais termos devem prever o pagamento de um montante fixo em todos os estados da natureza em que não ocorre o monitoramento. Nos estados em que é necessário o monitoramento (estados de inadimplência), o devedor entrega todo o seu produto ou receita para o credor. Trata-se de uma forma de se estabelecer uma relação perfeita entre ações tomadas pelo agente e resultados.

Pelo menos três características desse tipo de contrato contribuem para sua otimalidade (Dowd, 1992):

I) dispensa o monitoramento quando o estado da natureza é favorável aos termos do contrato, evitando-se assim custos contratuais desnecessários;

II) induz o devedor a minimizar a probabilidade de monitoramento (e, deste modo, minimizar o custo esperado de monitoramento), já que ele não ganha nada na situação de inadimplência;

III) considerando que o monitoramento depende do que o devedor alega em relação ao resultado do seu projeto, ele não terá incentivo em mentir, já que pode perder toda a sua receita relacionada com o investimento realizado. $^{7}$

Para que se entenda o arranjo contratual ótimo no caso da existência de assimetria de informação, considera-se inicialmente uma situação na qual a firma, já selecionada e que não possui colateral suficiente para oferecer como garantia do empréstimo já adquirido de $X$, se compromete, após determinado período, a quitar sua dívida no montante de $(1+\mathrm{r}) . \mathrm{X}$, sendo $\mathrm{r}$ a taxa de juros já pactuada. Na condução do projeto, a firma tem a opção de empenhar-se adequadamente, incorrendo assim num custo $\mathrm{C}$ (custo de empenho no projeto ou desutilidade do empenho) e recebendo uma receita igual a $\mathrm{B} 1$, suficiente para quitar a dívida. Caso escolha não se empenhar, o custo do empenho é igual a zero e a receita igual a B2, menor do que o custo da dívida. Em caso de inadimplência, o banco pode cobrar uma "taxa de garantia" igual a $f(0 \leq f \leq 1)$ sobre a receita auferida. Podemos representar os possíveis resultados desta situação a partir do quadro 1 a seguir: ${ }^{8}$

\footnotetext{
7 Dadas essas três justificativas, deve-se destacar que as ameaças do principal em fazer valer as cláusulas contratuais devem ser criveis. Muitas vezes, no entanto, é mais vantajoso para o principal a renegociação do contrato. Nesse caso, pode não ter sentido a idéia de contrato ótimo. Discuti-se esse ponto mais adiante

${ }^{8}$ Por simplicidade, estamos desconsiderando a taxa de captação do banco
} 
Quadro 1. Resultados de um modelo de empréstimo (i)

\begin{tabular}{|l|c|c|}
\hline \multicolumn{1}{|c|}{ Jogador } & O empréstimo é pago & O empréstimo não é pago \\
\hline Firma & $\mathrm{B} 1-(1+\mathrm{r}) \cdot \mathrm{X}-\mathrm{C}$ & $\mathrm{B} 2-\phi . \mathrm{B} 2$ \\
Banco & $(1+\mathrm{r}) \cdot \mathrm{X}-\mathrm{X}$ & $\phi . \mathrm{B} 2-\mathrm{X}$ \\
\hline
\end{tabular}

Pode-se notar que se B2 - $\phi$. B2 > B1 - $(1+r) . \mathrm{X}-\mathrm{C}$ para algum $\phi$, a firma poderá ter interesse em não se empenhar adequadamente e tornar-se inadimplente. Evidentemente, o banco escolherá $\phi=1$ de forma a induzir a firma a empenhar-se e pagar a dívida (supõe-se que B1 $-(1+r)$. $\mathrm{X}-\mathrm{C}>0$ ).

Considera-se agora uma situação em que ser verifica a existência de assimetria de informação, que se manifesta pela possibilidade da firma mentir sobre sua receita (B2* ao invés de $\mathrm{B} 2$ ) em caso de inadimplência, tendo como objetivo tirar proveito disso. Tal situação pode ser representada pelo quadro 2 a seguir:

Quadro 2. Resultados de um modelo simples de empréstimo (ii)

\begin{tabular}{|l|c|c|}
\hline \multicolumn{1}{|c|}{ Jogador } & O empréstimo é pago & O empréstimo não é pago \\
\hline Firma & $\mathrm{B} 1-(1+\mathrm{r}) . \mathrm{X}-\mathrm{C}$ & $\mathrm{B} 2-\phi . \mathrm{B} 2^{*}$ \\
Banco & $(1+\mathrm{r}) . \mathrm{X}-\mathrm{X}$ & $\phi . \mathrm{B} 2 *-\mathrm{X}$ \\
\hline
\end{tabular}

Supondo que B2 > B2* e B2 - $\phi . B 2 *>B 1-(1+r) . X-C$, para qualquer $\phi$ entre zero e um, haverá incentivos à firma em não se empenhar e mentir sobre sua receita. Nesse caso, será necessário estipular cláusulas contratuais que prevêem a atividade de verificação ou monitoramento por parte do banco de forma a tornar B2* = B2, induzindo a firma a empenhar-se adequadamente e pagar o empréstimo, caracterizando-se assim o contrato ótimo. Entretanto, a atividade de verificação resulta em custos para o banco de tal forma que seu payoff, em situação de inadimplência por parte da firma, será de $\phi . B 2$ - X - CV, onde CV representa o custo de verificação. Evidentemente, esse payoff deverá ser necessariamente maior do que $\phi . \mathrm{B} 2 *-\mathrm{X}$ para que seja do interesse do banco monitorar. Caso o contrário, a firma poderá ter incentivo em não se empenhar e mentir sobre sua receita. Por outro lado, existe um valor crítico, para CV, a partir do qual $\phi . B 2-\mathrm{X}-\mathrm{CV}$ torna-se negativo, não havendo incentivos, neste caso, para a concessão do empréstimo por parte do banco.

O grande problema dos contratos de empréstimos é exatamente a existência do custo de verificação, que pode inviabilizar determinados tipos de empreendimentos, mesmo aqueles que são viáveis economicamente. Este é 
o caso em que os resultados do empreendimento sofrem fortes influências de eventos aleatórios como o caso das atividades agrícolas e projetos de longo prazo. Por outro lado, é de se esperar um valor mínimo fixo para CV, justificado por uma estrutura mínima de administração das carteiras de empréstimo do banco. Se isso é verdade, para cada taxa de juros, existe um valor mínimo de empréstimo, abaixo do qual o banco não terá interesse em conceder o empréstimo. Neste caso, pequenos empreendimentos podem não estar sendo atendidos pelo mercado de crédito.

Cabe destacar que até então analisaram-se situações nas quais o banco oferece um contrato de empréstimos que prevê, no caso de inadimplência, uma taxa de garantia que incide sobre a receita auferida pelo empresário e a verificação da receita por ele declarada. Existem, no entanto, outras situações nas quais a garantia de pagamento de empréstimo assume a forma de bens (colateral) que fazem parte da riqueza do tomador (imóveis, terra, equipamentos etc.). Aparentemente, esse tipo de garantia apresenta duas vantagens sob o ponto de vista do banco: i) evita o custo de monitoramento em caso de inadimplência; e, ii) pode significar a garantia para o banco que ele receberá, ainda que sob a forma de bens, o valor total do empréstimo (colaterização total). Evidentemente, tal possibilidade mais uma vez pode estar excluindo empreendimentos viáveis, se o empreendedor não possui garantias reais suficientes para tal. Por outro lado, o colateral possui uma grande desvantagem: a baixa liquidez de determinados bens oferecidos como garantia. De qualquer forma, a exigência do colateral constitui-se num possível arranjo contratual ótimo.

Como conclusão dessa análise, pode-se afirmar que problemas de incentivo nas operações de crédito, decorrentes da existência de assimetria de informação em tais operações podem resultar em custos reais para os empréstimos na economia. Além disso, posturas mais conservadoras por parte dos bancos podem criar distorções na alocação de recursos, penalizando determinados grupos homogêneos. Este pode ser o caso das micro e pequenas empresas, principalmente aquelas do setor informal, em que os empresários geralmente não possui garantias reais para o empréstimo, além de necessitar quantias cujo pequeno montante não compensa o custo de gestão do empréstimo por parte do banco. O problema é particularmente delicado em países subdesenvolvidos ou ditos "em desenvolvimento", em que se verifica uma grande parcela da população próxima ou até mesmo abaixo da linha de pobreza. Em tais países, o setor informal e as micro e pequenas empresas assumem importante papel na geração de emprego e renda. Assim, nesses países, o mercado de crédito pode não estar cumprindo eficientemente seu papel de indutor do desenvolvimento. 


\section{Viabilizando o crédito para pequenos empreendimentos: o caso do Grameen Bank}

Inúmeras experiências internacionais têm demonstrado que, apesar dos problemas informacionais e custos operacionais presentes nos empréstimos, é possível criar arranjos contratuais que viabilizem o crédito a pequenos empreendimentos. A experiência mais antiga nesse sentido deve-se ao Gramenn Bank ou Banco do Povo, de Bangladesh, que vem atuando desde $1976 \mathrm{em}$ praticamente todos os povoados do país. Seu surgimento deu-se praticamente por acaso, com a iniciativa de um professor de economia da Universidade de Chittagong, Muhammad Yunus. Indignado com o estado de pobreza de seu país e surpreso com a insistência de diversas famílias em conduzir um negócio próprio naquela situação, recorrendo muitas vezes a "agiotas" que exigiam juros extorsivos para os empréstimos, o professor Yunus passou a emprestar de seu próprio bolso pequenas quantias a título de empréstimo, obtendo o retorno nos prazos estabelecidos. Tal iniciativa acabou por dar início a mais bem-sucedida e respeitável experiência na área de microcrédito sem a participação do setor público. Após 23 anos de atuação, o Gramenn Bank empresta somas anuais que ultrapassam os US\$ 300 milhões, atendendo mais de 2 milhões de pessoas. Entre sua clientela, predominam mulheres de baixa renda, sendo de US\$ 170 a média dos empréstimos. Tudo isso sem subsídios, comuns em financiamentos de atividades sociais.

Desde o início de suas operações, o banco vem descartando a exigência de garantias reais para a concessão dos empréstimos por considerá-las discriminatórias contra os pequenos empreendimentos. A garantia se dá a partir de um esquema de fiança solidária, em que o empréstimo é concedido a um pequeno grupo de pessoas, sendo todos os membros do grupo responsáveis pela dívida.

O sucesso do Grameen Bank se traduz pelo crescente volume de empréstimos concedidos a cada ano e pelas reduzidas taxas de inadimplência, conforme pode ser visualizado a partir das tabelas a seguir.

Analisando os dados, percebe-se, no período, uma trajetória nitidamente crescente no volume de empréstimos concedidos e número de pessoas beneficiadas. Nota-se ainda índices de inadimplência próximo de zero em quase todo o período.

O grande sucesso desta instituição está exatamente no tipo de arranjo contratual presente em suas operações de crédito e que busca reduzir o custo de seleção e monitoração do empréstimo, além de criar incentivos ao pagamento do mesmo, contribuindo assim para reduzir o risco de inadimplência das operações. Conforme destacado anteriormente, tal arranjo é desenhado a 
Tabela 1. Dados históricos do Grameen Bank - 1980/85/90/95/97

\begin{tabular}{lccccc}
\hline \multicolumn{1}{c}{ Descrição } & 1980 & 1985 & 1990 & 1995 & 1997 \\
\hline Volume de empréstimos (em US\$ milhões) & 1,10 & 17,16 & 91,14 & 361,62 & 385,77 \\
Taxa de retorno dos empréstimos (\%) & 100 & 99,30 & 98,76 & 99,28 & 93,18 \\
$\mathrm{n}^{\circ}$. de pessoas contempladas & 14830 & 171.622 & 869.538 & 2.065 .661 & 2.272 .503 \\
Valor médio dos empréstimos & 74 & 100 & 105 & 175 & 170 \\
\hline
\end{tabular}

Fonte: Gramenn Bank

Obs.: * valores emUS\$

** desembolso/ano

partir de um sistema de fiança solidária, em que o empréstimo é concedido coletivamente a grupos solidários, de cinco pessoas. Inicialmente, apenas dois membros do grupo recebem o empréstimo. Condicionado ao cumprimento contratual por parte destes dois membros, é concedido, num segundo momento, o empréstimo aos demais. Em cada grupo, todos respondem pela dívida contraída e pelo cumprimento das cláusulas contratuais, particularmente com relação aos prazos de reembolso dos empréstimos. Cria-se assim um sistema de auto-seleção e automonitoração dentro do grupo, que tende a reduzir os problemas de seleção adversa e risco moral, além de diminuir os custos de gestão das carteira de empréstimo pelo banco. Os empréstimos em geral são de curto prazo (12 meses em média) e a sua renovação, inclusive com a possibilidade de uma quantia superior ao anteriormente concedido, depende da quitação das dívidas anteriores dentro dos prazos estabelecidos. Nesse sentido, a possibilidade de dispor de novos empréstimos constitui-se num grande incentivo ao reembolso da dívida.

Além das características gerais dos contratos que caracterizam as operações de crédito realizado pelo Grameen Bank, existem ainda algumas características particulares inerentes às micro e pequenas empresas que atuam no sentido de reduzir o risco das operações de microcrédito. Em primeiro lugar, pode-se argumentar que existe um grande incentivo ao pequeno empreendedor em conduzir seu negócio de forma adequada. Tal incentivo é baseado em duas características dos pequenos empreendimentos: i) constitui-se em fonte quase que exclusiva de sobrevivência do empreendedor e de sua família; ii) o fato dele ser caracterizado pela não separação entre gerência e propriedade, o que é um incentivo à condução ótima do negócio. ${ }^{9}$ Em segundo lugar, a estrutura simplificada e de pequeno porte de tais empreen-

\footnotetext{
${ }^{9}$ Sob as implicações da separação dos conceitos de gerência e propriedade, ver Jensen, M. e Meckling (1976).
} 
dimentos permite grande poder de manobra em respostas a mudanças demandadas pelo mercado ou decorrentes de alterações não antecipadas na conjuntura macroeconômica.

Um ponto que deve ser destacado em relação às instituições de microcrédito é a substituição dos procedimentos burocráticos pela proximidade com o cliente. Nessas instituições, o agente de crédito desempenha um importante papel por estar próximo da comunidade, colaborando para identificar oportunidades de negócios, para colaborar na organização dos empreendimentos, na elaboração dos projetos e no treinamento dos tomadores de recursos para viabilizar a sobrevivência futura do empreendimento. Apesar do custo mais elevado do financiamento de pequenos empreendimentos devido à pequena escala dos empréstimos, a experiência tem mostrado que o principal problema das microempresas não é o custo do empréstimo, pois estas parecem ter oportunidades de investimento compatíveis com o custo, mas o acesso ao crédito. Assim, mesmo com taxas de juros relativamente mais altas, verifica-se o baixo índice de inadimplência dessas instituições.

Além do Grameen Bank, existem inúmeras outras instituições de microcrédito espalhadas pelo mundo que confirmam o sucesso deste tipo de empreendimento. Em geral, todas estas instituições seguem um esquema de empréstimo semelhante ao descrido para o Grameen Bank. Dentre as mais atuantes pode-se destacar o Banco Rakyat, na Indonésia, criado no início dos anos 70 e que atua predominantemente na zona rural do país; o Programa de Empresa Rural do Quênia, criado em 1984, atuante junto às comunidades pobres tanto nas áreas urbanas quanto rurais; e o Banco Solidário S.A, também conhecido como BancoSol, que atua junto a microempresas nas cidades da Bolívia, tendo suas atividades iniciadas em 1992. ${ }^{10}$

\section{A experiência brasileira de microcrédito}

Já vem de longa data, a preocupação das autoridades brasileiras com o financiamento de setores que seriam naturalmente excluídos do sistema financeiro tradicional quer pelo elevado risco quer pelo elevado custo de transação. A forma assumida pelas políticas que visavam eliminar este problema era a criação de entidades financeiras, ou linhas de crédito específicas para determinados segmentos (agricultura, pequena e micro empresa, ${ }^{11}$ etc.) ou o direcionamento dos recursos bancários (basicamente depósitos à

${ }^{10}$ Um relato acerca das diversas experiências mundiais pode ser encontrada na publicação $O$ Correiro da Unesco (1997). No caso das experiências nacionais, ver Revista Rumos (1998).

$"$ Sobre as dificuldades de financiamento das micro empresas no Brasil ver Sebrae/Gepep (1997). 
vista). Estas políticas acabavam se traduzindo em subsídios ou amplos programas de renegociações de dívida com grande ônus para o poder público.

A instabilidade econômica vivida nas últimas décadas trouxe algumas conseqüências no sistema financeiro: (i) profunda retração nas operações de crédito com os intermediários financeiros transformando-se em "corretores da dívida pública"; isto levou ao desaparecimento de políticas de crédito ativas e mesmo na perda de "expertise" na concessão de crédito (desmantelamento de setores de análise de risco de crédito e assim por diante); e, (ii) a aceleração inflacionária levou a uma profunda retração nos depósitos à vista sobre os quais incidiam grande parte das regulamentações sobre o direcionamento de crédito; assim as chamadas linhas especiais passaram a ficar dependentes de aportes de recursos fiscais ou de imposições junto ao Sistema Financeiro oficial.

A ausência de políticas desenvolvimentistas nacionais, as pressões privatizantes e a ausência de recursos públicos, com a crise fiscal, alteraram a própria lógica de atuação das instituições financeiras públicas que deixaram de atuar como "agentes desenvolvimentistas" ou com critérios sociais e passaram a lutar pela sobrevivência adotando na maior parte dos casos critérios de eficiência privados para a definição de suas políticas operacionais. Este parece ter sido o caso do BNDES, nos anos 80, do Banco do Brasil e da Caixa Econômica Federal, nos anos recentes e, em escala reduzida no BNB, que como administrador do Fundo do Nordeste, continuou com a feição de uma agência regional de desenvolvimento.

Com a estabilização econômica, advinda com o Plano Real, os bancos perderam sua principal fonte de receita, os lucros inflacionários decorrentes do "floating", e tiveram que se transformar em bancos de fato, isto é, em instituições que intermedeiam recursos e concedem crédito para poderem obter receitas.

Em um primeiro momento, esta necessidade veio ao encontro do amplo crescimento da demanda de crédito propiciada pela estabilização: crédito ao consumidor; investimento; etc. Tão logo veio a primeira reversão econômica no início de 1995, os índices de inadimplência assumiram patamares assustadores mostrando os elevados riscos associados à concessão de crédito, dadas as profundas incertezas que pairam sobre a economia brasileira, $\mathrm{e}$ a falta de capacidade dos bancos em fazer seu negócio tradicional.

Esta situação, por um lado, ampliou o "conservadorismo" na análise de crédito e, por outro lado, ampliou os spreads bancários encarecendo os recursos para os tomadores finais. Em relação ao primeiro aspecto, deve-se destacar que os bancos passaram a exigir maiores garantias reais; demonstrações contábeis que atestem um faturamento adequado (e outros comprovantes); carteira de trabalho assinada, etc. Se considera-se que no Brasil a 
maior parte dos estabelecimentos são micro empresas que escondem seu faturamento para diminuir a carga tributária e que metade dos trabalhadores não possuem carteira assinada, conclui-se que o Sistema Financeiro Tradicional exclui a maior parte da população e das empresas do acesso ao crédito. Assim, o instrumento do microcrédito que visa à geração de emprego e renda pela inserção de novos atores ao processo produtivo dificilmente se enquadraria no sistema financeiro.

Mas, por outro lado, alguns fatores criaram o ambiente para o surgimento do microcrédito no país. Em primeiro lugar, como já destacou-se, está o crescimento das instituições de microcrédito no mundo. Tem-se assistido o surgimento de redes de instituições, de diferentes formatos, sendo que várias delas se estruturam em torno de incentivos e aportes de recursos de agências internacionais, com destaque para o Banco Interamericano de Desenvolvimento (BID). Em geral, as instituições de microcrédito, no Brasil, organizam-se na forma de ONG's (Organizações Não-Governamentais), assim não recebem depósitos, emprestando recursos próprios e doações. As principais instituições brasileiras são a Portosol de Porto Alegre; o Banco da Mulher na Bahia; a Rede CEAPE, o BRB Trabalho no Distrito Federal, entre outros.

Em segundo lugar, deve-se destacar as possibilidades abertas pela criação do FAT (Fundo de Amparo do Trabalhador) para o financiamento do seguro-desemprego. O FAT tem seus recursos provenientes da arrecadação do PIS/PASEP, sendo que $40 \%$ destinam-se ao financiamento de investimentos, administrado pelo BNDES (principal fonte de recursos do Banco), e $60 \%$ ao suporte do "Programa de Seguro Desemprego". Note-se que diferentemente de outros fundos, existe flexibilidade na utilização dos recursos, possibilitando o desenvolvimento de vários programas voltados ao mercado de trabalho. Assim, os recursos do FAT não se direcionam apenas para a política passiva de assistir o desemprego, mas é utilizado para ajudar a manter os empregos existentes; criar novos empregos e facilitar a empregabilidade dos trabalhadores, isto é, políticas ativas no mercado de trabalho que atuam tanto sobre a oferta como sobre a demanda. Entre os principais exemplos pode-se destacar o PLANFOR (Programa de Formação Profissional), o direcionamento de recursos para o crédito agrícola; para a FINEP, etc. O FAT foi se consolidando como a principal fonte de recursos para o financiamento de longo prazo na economia, o BNDES tem grande autonomia na alocação dos recursos direcionados para programas de investimento devendo apenas respeitar os critérios de remuneração do fundo.

Todo este contexto possibilitou o surgimento do PROGER (Programa de Geração de Emprego e Renda). Este pode ser considerado como um programa federal de microcrédito que visa estimular o emprego a partir dos 
pequenos e microempreendimentos com base nos recursos do FAT, que excede o necessário para o pagamento do Seguro Desemprego e do Abono Salarial. Além das micro e pequena empresas o PROGER atende os recémformados e abre a possibilidade de atendimento ao setor informal. Inicialmente o programa visava atender apenas às atividades urbanas, mas com a falta de recursos para o crédito agrícola, criou-se o PROGER - Rural.

O PROGER introduziu algumas inovações em relação às linhas de financiamento tradicionais, aproximando-o das experiências internacionais de microcrédito. Deve-se destacar, em relação a este aspecto, a operacionalização descentralizada, a existência de critérios de controle social e programas de treinamento e acompanhamento dos beneficiários acoplados ao financiamento.

A operacionalização do PROGER envolve, além do CODEFAT (Conselho Deliberativo do Fundo de Amparo ao Trabalhador) que define as regras de liberação dos recursos, mais três agentes: a comissão municipal de emprego (CME), o agente financeiro (AF) e a entidade credenciada (EC). A existência da CME é a pré-condição para que um município qualquer tenha acesso aos recursos. Suas funções são articular-se com instituições e organizações envolvidas no programa integrando suas ações e indicar áreas e setores prioritários para a alocação de recursos. À EC, que pode ser o SEBRAE, às universidades ou outras, cabe a elaboração dos projetos, o acompanhamento de sua execução e a capacitação gerencial dos beneficiários, além de poder fornecer suporte à $\mathrm{CME}$ na definição das prioridades. $\mathrm{E}$, ao AF cabe a montagem da operação de empréstimo, a concessão do financiamento e a prestação de contas ao CODEFAT. Este último que assume o risco do crédito.

Os agentes financeiros do PROGER são os bancos oficiais: Banco do Brasil (BB), Banco do Nordeste do Brasil (BNB) e Caixa Econômica Federal (CEF). Cada agente tem suas próprias definições sobre linhas e formas de atuação e são eles em última instância que definem quanto e para quem os recursos serão liberados.

Ao entregar o PROGER para agentes envolvidos no Sistema Financeiro Tradicional, este foi assumindo o caráter de mais um produto dentro dos bancos e, como tal, a análise das demandas e a liberação dos recursos seguiam trâmites semelhantes ao das outras linhas de financiamento, não possibilitando que o PROGER atingisse os objetivos propostos pelas dificuldades já levantadas em relação ao financiamento dos segmentos ao qual se destina o PROGER; e a incapacidade desses agentes em atuar de forma próxima a esta clientela.

Além disso, as vantagens apontadas de controle social pela articulação com os agentes locais parecem não ter se materializado pelo elevado poder / centralidade do agente financeiro no processo; assim as comissões munici- 
pais de emprego e as entidades parceiras parecem ter assumido papel decorativo na operação.

Os trabalhos existentes para a avaliação do PROGER $^{12}$ mostram a maior importância das liberações rurais em relação à urbana, sinalizando que o programa afastou-se do objetivo inicial de geração de emprego e renda e foi transformando-se em mais uma fonte de recursos para o financiamento de pequenos produtores rurais juntando-se ao PRONAF e ao PROCERA; o que inclusive determinou a maior importância da Região Sul no total de recursos liberados.

O desempenho do PROGER é muito diferenciado de acordo com o agente financeiro considerado. Este caráter rural decorre basicamente do grande volume de recursos aplicados pelo BB no PROGER - Rural e sua pequena atuação no meio urbano. $O$ agente financeiro que parece estar apresentando o melhor desempenho é o BNB. Foi a instituição que realizou maior número de contratos e maior volume de liberações no PROGER Urbano; atuando basicamente neste segmento, isto é, com uma baixa participação do PROGER - Rural. Isto explica por que apenas no Nordeste, o PROGER - Urbano é mais significativo que o rural. O melhor desempenho do $\mathrm{BNB}$, que foi responsável por $75 \%$ do número de contratos e $66 \%$ do valor liberado pelo PROGER - Urbano no período 95/97; decorre do fato desta instituição já vir atuando como uma agência de desenvolvimento regional e não como um típico banco comercial, o que lhe permite flexibilizar as operações de crédito, atuando com diferentes tipos de garantias, isto é, adaptando-as às necessidades da clientela.

Apesar da menor rigidez do BNB, chama a atenção que este apresentou uma taxa de inadimplência no PROGER (tanto rural como urbano) inferior ao Banco do Brasil, no caso da área urbana, 2,9\% de inadimplência para o primeiro e $6,5 \%$ para o segundo. Este resultado pode estar relacionado ao fato de o BNB estar mais próximo das formas de atuação das instituições de microcrédito internacionais com a presença de agentes de crédito junto à comunidade e substituindo os procedimentos burocráticos pela flexibilidade requerida neste tipo de atuação.

De uma forma geral, independente do agente financeiro, têm-se levantado os seguintes problemas na operacionalização do PROGER (Valle, B., 1998 p. 242-243):

(I) fraca atuação das Comissões de Emprego (especialmente na definição de prioridades e acompanhamento);

(II) pouca integração com as ações de qualificação técnica e gerencial;

(III) reduzidas ações de acompanhamento;

${ }^{12}$ Ver a respeito Guimarães (1998), Valle (1998) e Azeredo (1998). 
(IV) elevada seletividade da clientela do programa pelos agentes financeiros para empresas já constituídas e profissionais de nível superior;

(V) burocratização e exigências de garantia na concessão de crédito;

(VI) pouca vinculação entre os empreendimentos financiados e as necessidades do mercado, dados os restritos estudos das oportunidades de investimento.

Note-se que estes problemas decorrem do que já foi levantado: o poder decisório para liberação do crédito é do agente financeiro e este é um banco comercial; como o custo de monitoramento é elevado, sendo relativamente maior para os pequenos negócios, estes dificultam as liberações; neste caso as comissões e/ou os agentes locais que deveriam acompanhar o financiamento acabam ficando sem qualquer atribuição no PROGER. São por esses motivos que o BNB, que não atua tanto como um banco comercial, tem apresentado o melhor desempenho.

Se é este o caso, pode-se contrapor a experiência do PROGER com instituições locais de microcrédito. Dois exemplos citados na literatura são a ICC - Portosol e o BRB Trabalho; ambos iniciados no final de 1995. (Guimarães, 1998, p. 219). As duas instituições apresentaram um grande crescimento no número de contratos, os valores são relativamente baixos (em torno de $\mathrm{R} \$ 1.500,00$ ); apresentam uma elevada participação de mulheres entre os tomadores e operam com prazos curtos. Ou seja, as características são semelhantes aos modelos internacionais. As operações de crédito são desburocratizadas, utilizam formas contratuais alternativas (aval solidário, grupos, etc.) e suas operações tem por base a figura do "agente de crédito", que convive junto à comunidade, identifica oportunidades, busca os tomadores de recursos, monitora a utilização dos recursos, oferece suporte técnico e possui grande poder para determinar a concessão do crédito, pois é quem possui melhores condição de avaliar o risco da operação.

As tabelas abaixo permitem avaliar a evolução dos créditos da Rede CEAPE e alguns indicadores da Portosol.

Estas experiências têm levado ao surgimento de uma série de novas instituições de microcrédito pelo país: São José dos Campos, Juiz de Fora, Santo André, Rio de Janeiro, etc. A forma de operação e a constituição dos funding é muito semelhante em todos os casos.

$O$ espaço que vem sendo ocupado por estas instituições confirmam que o financiamento de microempreendimentos e dos segmentos não inseridos no processo produtivo não é possível dentro da estrutura tradicional do sistema financeiro, isto requer modelos mais flexíveis e mais próximos do público-alvo. Este modelo, por outro lado, dada a relativa fragilidade das instituições, e a baixa capilaridade, não possibilita que elas gerem uma política mais ampla e integrada de geração de emprego e desenvolvimento; elas acabam atuando de forma mais pontual. 
Tabela 2. Dados CEAPE 1992/1998

\begin{tabular}{c|c|c|c}
\hline$\cdots$ Ano & Valor dos Créditos* & Número de Créditos & Valor Médio dos Créditos* \\
\hline 1992 & 553.458 & 3.194 & 173 \\
1993 & 1.735 .025 & 5.140 & 338 \\
1994 & 5.647 .653 & 7.658 & 737 \\
1995 & 9.449 .038 & 9.068 & 1.042 \\
1996 & 18.007 .655 & 17.677 & 1.019 \\
1997 & 25.315 .950 & 30.746 & 823 \\
1998 & 34.481 .557 & 44.105 & 782 \\
\hline
\end{tabular}

* valores em US\$

Tabela 3. Dados estatísticos em 31/03/1999

\begin{tabular}{|c|c|c|c|c|}
\hline \multicolumn{2}{|c|}{ (i) Histórico } & \multicolumn{3}{|c|}{ (ii) Distribuição } \\
\hline Valor Total Emprestado & $12.710 .250,27$ & Por sexo & $\begin{array}{l}\text { Homens } \\
\text { Mutheres }\end{array}$ & $\begin{array}{l}51 \% \\
49 \% \\
\end{array}$ \\
\hline $\begin{array}{l}\text { Total dos Créditos } \\
\text { Concedidos }\end{array}$ & $7.652,00$ & \multirow{2}{*}{ Por atividade } & \multirow{2}{*}{$\begin{array}{l}\text { Produção } \\
\text { Comércio } \\
\text { Serviço }\end{array}$} & \multirow{2}{*}{$\begin{array}{l}14 \% \\
32 \% \\
54 \%\end{array}$} \\
\hline $\begin{array}{l}\text { Valor Médio dos Créditos } \\
\text { Ativos }\end{array}$ & $1.661,04$ & & & \\
\hline$\overline{\text { Carteira Ativa }}$ & $1.856 .142,51$ & \multirow{3}{*}{ Por faixas de crédito } & \multirow{3}{*}{$\begin{array}{l}\mathrm{R} \$ 200-1.500 \\
\mathrm{R} \$ 1.501-3.000 \\
\text { Mais de } 3.000\end{array}$} & \multirow{3}{*}{$\begin{array}{l}53 \% \\
24 \% \\
23 \%\end{array}$} \\
\hline Número de Clientes Ativos & $1.700,00$ & & & \\
\hline $\begin{array}{l}\text { Valor Médio dos Créditos } \\
\text { Ativos }\end{array}$ & $1.091,85$ & & & \\
\hline Inadimplência & $5 \%$ & \multirow[b]{2}{*}{ Por tipo de garantia } & \multirow{2}{*}{$\begin{array}{l}\text { Aval } \\
\text { Real } \\
\text { Solidária } \\
\text { Mista }\end{array}$} & \multirow{2}{*}{$\begin{array}{c}61 \% \\
20 \% \\
14 \% \\
5 \%\end{array}$} \\
\hline $\begin{array}{l}\text { \% de renovação dos créditos } \\
\text { quitados }\end{array}$ & $70 \%$ & & & \\
\hline
\end{tabular}

* valores em US\$

A criação do Crédito Produtivo Popular do BNDES (BNDES Trabalhador e BNDES Solidário) pode ser a alavanca para o crescimento das instituições de microcrédito no país potencializando o alcance deste instrumento. A grande vantagem desta linha é tentar atingir o pequeno empreendedor não por meio do sistema financeiro tradicional mas através do repasse de recursos às Secretarias do Trabalho e às ONG's voltadas ao microcrédito. Outro aspecto positivo é a possibilidade de potencializar o efeito do microcrédito, enquanto política de desenvolvimento, por permitir, através do BNDES, que o programa ganhe maiores dimensões e seja executado de forma mais integrada com outras políticas. 
Além disso, deve-se destacar que o governo federal lançou recentemente a Resolução 2.627 do Banco Central que dispõe sobre a constituição e o funcionamento de sociedades de crédito ao microempreendedor. Assim, desconsiderando-se o PROGER pode-se pensar que somente agora o microcrédito pode transformar-se efetivamente em um instrumento voltado à geração de emprego e renda na economia brasileira.

\section{Conclusão}

Este artigo tentou mostrar que o sistema financeiro tradicional na presença de informações assimétricas tende a excluir importantes segmentos econômicos, com destaque para as micro e pequena empresas e o setor informal. A importância destes segmentos nos países em desenvolvimento na geração de emprego e renda tende a limitar a eficiência da atuação do sistema financeiro tradicional. Mostrou-se que o problema não é necessariamente a inexistência de recursos, prazos ou taxas de juros que afugentam as micro empresas do acesso ao crédito, mas sim o desenho contratual do empréstimo e a forma de seleção dos tomadores. Para tal, tomando o caso brasileiro, analisou-se o Proger, uma linha de financiamento do governo federal para empresas de pequeno porte, mas que não atinge o público-alvo.

Como o sistema financeiro tradicional não alcança as micro e pequenas empresas, têm surgido em diversos países novos arranjos contratuais que se manifestam através de instituições de microcrédito. Os empréstimos concedidós por tais instituições baseiam-se num sistema de fiança solidária e empréstimos progressivos que tendem a reduzir cústos de seleção e monitoramento. As experiências apontam para uma nova alternativa que atenda parte dos empreendimentos produtivos discriminados pelo sistema financeiro tradicional, sem a necessidade de subsídios e demais programas assistencialistas por parte do governo, bastando garantir o acesso ao crédito. $\mathrm{O}$ sucesso alcançado por essas instituições decorre da desburocratização das operações de crédito e da proximidade com os tomadores, sendo a fígura central na alocação dos recursos, no acompanhamento e no suporte aos empreendimentos, o agente de crédito. A experiência brasileira mostra que o PROGER, enquanto executado dentro das regras do Sistema Financeiro tradicional, não consegue atingir seus objetivos, assim torna-se necessário criar uma rede de instituições mais flexíveis e que estejam mais próximas dos tomadores para garantir a viabilidade do microcrédito.

Cabe destacar que as restrições que atingem os menos favorecidos não se resumem apenas à falta de crédito. Se esta é uma restrição importante, não se deve esquecer da escassez de tecnologia, qualificação, infra-estrutura, etc. como 
fatores que limitàm as ações de um programa de combate à pobreza. Assim, só tem sentido o desenvolvimento de um programa de microcrédito, se este for inserido dentro de um plano de geração de emprego e renda mais amplo, com participação não apenas do governo, mas de outros segmentos da sociedade civil. E, o próprio microcrédito, deve ser acompanhado com atividades de suporte e treinamento dos microempreendedores.

\section{Referências bibliográficas}

AZEREDO, B. (1998). "Políticas Públicas de Geração de Emprego no Brasil: Limites e Possibilidades"; In: Oliveira, M. ${ }^{a}$ (org) Reforma do Estado \& Politicas de Emprego no Brasil; Campinas, UNICAMP, Instituto de Economia. p. 125-168.

BRAGA, M. B. (1998). A Economia da Informação e os Mercados de Crédito: Algumas Contribuições Teóricas à Moderna Teoria da Intermediação Financeira. Tese de Doutorado. São Paulo, IPE/USP.

O Correio da Unesco, (1997). Ano 23, no. 3, março de 1997. Brasil

DOWD, K. 1992. Optimal financial contracts. Oxford Economic Papers. 44 (1992), 672-693.

FRY, M. J. (1997) In Favour of Financial Liberalisation in The Economic Journal; May 1997.

GERTLER, M. (1988) Financial Structure and Aggregate Economic Activity: An Overview in Journal of Money Credit and Banking, vol. 20 August 1988.

GUIMARÃES, (1998) "Avaliação Geral dos Programas de Geração de Emprego e Renda”, In: Oliveira, M. ${ }^{a}$ (org) Op. cit. p. 193-223.

LEVINE, R. (1997) Financial Development and Economic Growth: Views and Agenda in Journal of Economic Literature, vol XXXV June 1997.

MANKIW, N. G. 1986. The allocation of credit and financial collapse. The Quarterly Journal of Economics. August, vol CI, issue 3.

MCKINNON, R. (1988) Financial Liberalization in Retrospect: Interest Rate Policies in LDCs; In: Ranis, G. e Shultz, T. The State of Development Economics: Progress and Perspectives; Oxford; Brasil Blackwell.

SEBRAE/GEPEP (1997) Sondagem Balcão - A Voz e A Vez dos Pequenos Empresários: Financiamento e Preços, vol 6, n 5, Agosto 1997

SHAW, E. (1973) Financial Deepening in Economic Development; New York; Oxford University Press.

STIGLITZ, J. E. (1990) Governo, Mercado Financeiro e Desenvolvimento Econômico in Revista Brasileira de Economia, vol 44, $\mathrm{n}^{\circ} 3$.

STIGLITZ, J. E. E WEISS, A. (1981) Credit Rationing in Markets with Imperfect Information in The American Economic Review, vol 71, $\mathrm{n}^{\circ} 3$

TOWNSEND. R. 1979. Optimal contracts and competitive markets with costly state verification. Journal of Economic Theory, 21. 265-93.

VALLE, B. (1998) "Políticas de Mercado de Trabalho no Brasil: A Experiência do PROGER" In: Oliveira, M. ${ }^{a}$ (org) op. cit., p. 225-246. 